\title{
Pharmacological management of claudication
}

\author{
Nivas Balasubramaniyam* \\ Interventional Cardiology Fellow, Icahn School of Medicine at Mount Sinai, New York, NY, USA
}

Available evidence suggests supervised exercise program is the most effective therapy for claudication. All patients with peripheral arterial disease (PAD) should undergo effective management to control their risk factors. In addition to risk factor control, the pharmacological management of PAD includes aspirin (with or without dipyridamole), clopidogrel, cilostazol, and pentoxifylline. Since the antiplatelet therapies were discussed in my previous communication, here we will restrict our discussion to cilostazol and pentoxifylline. Patients with mild to moderate symptoms are best treated by conservative measures such as exercise programs. Pharmacotherapy for claudication can be added on to the exercise regimen, no agent has been shown to have sufficient efficacy to gain wide spread acceptance. While studies have shown to improve treadmill walking distance, lack of robust clinical impact has limited their widespread use [1].

Pentoxifylline: Pentoxifylline is a methylxanthine derivative, approved in 1984 for claudication, increases the deformability of RBC's and WBC's, lowers fibrinogen levels and has antiplatelet effects [2]. A meta-analysis of pentoxifylline studies had found an increase of $44 \mathrm{~m}$ in maximal treadmill distance (95 percent confidence interval, 14 to 74 ) [3]. Two meta-analysis and two more systematic review published on pentoxifylline came to a conclusion that the drug might have a small benefit but lacks conclusive evidence to support wide spread use.

Cilostazol: Approved in 1999 by the FDA, this is a phosphodiesterase type 3 inhibitor (PDE-3), which inhibits platelet aggregation, formation of arterial thrombi, vascular smooth muscle proliferation and causes vasodilatation.However, since vasodilators and antiplatelet agents fail to improve claudication, the mechanism of action of this agent is unknown. It is extensively metabolized by cytochrome P450 enzyme system (CYP 3A4 isoform) in the liver enabling the drugs which inhibit this enzyme to increase its concentration. In four randomized placebo control trials, cilostazol has been shown to be superior to placebo in improving the pain free and maximal treadmill walking distance [47]. The predominant side effect of cilostazol is headache, which affects 34 percent of patients taking $100 \mathrm{mg}$ twice daily, as compared with 14 percent of patients taking placebo. The other side effects are transient diarrhea, palpitations and dizziness. Since cilostazol is a PDE-3 inhibitor like milrinone which has been shown to increase mortality in chronic heart failure, this comes with a black box warning not to use in patients with claudication and heart failure.

\section{References}

1. Ouriel K (2001) Peripheral arterial disease. Lancet 358: 1257-1264. [Crossref]

2. Samlaska CP, Winfield EA (1994) Pentoxifylline. J Am Acad Dermatol 30: 603-621. [Crossref]

3. Girolami B, Bernardi E, Prins MH, Ten Cate JW, Hettiarachchi R, et al. (1999) Treatment of intermittent claudication with physical training, smoking cessation, pentoxifylline, or nafronyl: a meta-analysis. Arch Intern Med 159: 337-345. [Crossref]

4. Dawson DL1, Cutler BS, Hiatt WR, Hobson RW 2nd, Martin JD, et al. (2000) A comparison of cilostazol and pentoxifylline for treating intermittent claudication. Am J Med 109: 523-530. [Crossref]

5. Dawson DL, Cutler BS, Meissner MH, Strandness DEJ (1998) Cilostazol has beneficial effects in treatment of intermittent claudication: results from a multicenter, randomized, prospective, double-blind trial. Circulation 98: 678-686. [Crossref]

6. Money SR, Herd JA, Isaacsohn JL, Davidson M, Cutler B, et al. (1998) Effect of cilostazol on walking distances in patients with intermittent claudication caused by peripheral vascular disease. J Vasc Surg 27: 267-274. [Crossref]

7. Beebe HG, Dawson DL, Cutler BS, Herd JA, Strandness DE Jr, et al. (1999) A new pharmacological treatment for intermittent claudication: results of a randomized, multicenter trial. Arch Intern Med 159: 2041-2050. [Crossref]
Copyright: (C2017 Balasubramaniyam N. This is an open-access article distributed under the terms of the Creative Commons Attribution License, which permits unrestricted use, distribution, and reproduction in any medium, provided the original author and source are credited.
Correspondence to: Nivas Balasubramaniyam, Interventional Cardiology Fellow, Icahn School of Medicine at Mount Sinai, New York, NY, USA, E-mail: nivaseras@gmail.com

Received: May 22, 2017; Accepted: June 05, 2017; Published: June 08, 2017 